through a tube passed into the stomach and with the food. Some of the rabbits took an immense quantity of alcohol extending over a period of three or four months before the phenomena began to present themselves, while others succumbed very rapidly and with a smaller quantity. During the time of the experiments symptoms of poisoning, as diminution of weight, stupor, weakness, tremor of the tongue and buccal mucous membrane, and often general tremor and a condition like delirium tremens was present. The corneal reflex disappeared before the ciliary. After death the experimenter paid little attention to the parts other than the peripheral nerves. In the nerves examined, such as to auricular, tibial, vagus, etc., the evidences of degeneration in the medullary sheaths, as is frequently seen and described, were found. In the axis cylinder, moreover, was found a condition which the author says is as yet unknown in the literature. The axis cylinders were wound spirally on their continuity, or corkscrew-like, and in some cases they were in knots. The author inclines to think that this condition is pathological.

\title{
ON THE TOPOGRAPHY OF THE NUCLEAR CHANGES IN AMYOTROPHIC LATERAL SCLEROSIS.
}

Dr. W. Muratoff (Neurolog. Centralbl., No. I7, I89I). The author gives the results of his anatomical investigations in three cases of amyotrophic lateral sclerosis. The changes in the gray substance were atrophy of the principal nucleus of the hypoglossal and of the root of the hypoglossal. Roller's nucleus intact. The posterior nucleus of vagus somewhat atrophied. Nucleus ambiguus normal. Glosso-pharyngeal nucleus normal. Facial nucleus in one case distinctly atrophied, in the other two, very much less so. Atrophy of knee and fibres of the facial where it bends over the abducens nucleus. Abducens nucleus normal. In one case the motor nucleus of the trigeminus was somewhat atrophied. No change in the motor-oculi nucleus.

The changes in the white substance were sclerosis in the entire extent of the pyramids. Some degeneration at the ventral border of substantia nigra of Soemmering. The change in the posterior columns was not very distinctly marked but always present, particularly in the case that had such marked changes in the nucleus of the twelfth nerve. And in a case of the disease where the nucleus of the twelfth 
was not affected, the posterior columns were found to be normal. The affection of the posterior bundle was in all three cases in entire accordance with the changes in the nuclei. The changes in the spinal cord were those ordinarily found. From his observations the writer believes the following conclusions are justifiable in regard to the anatomical changes in this disease.

I. The posterior bundle can, as the result of atrophy of the nuclei, become diseased. This is not a secondary degeneration, but a primary systemic affection.

2. In the posterior bundle are found short commissural fibres, the functions of which are unknown.

3. On developmental grounds and from pathologicoanatomical observations, there is a certain analogy between the ground bundle of the anterior column and the posterior longitudinal bundle.

4. Degeneration of the raphe and fillet.

\section{A REMARK ON THE OUTER NUCLEUS OF THE FUNICULUS CUNEATUS.}

By Dr. L. Blumenan (Neurolog. Centralbl., No. I9, I89I). Further remarks are added by this writer to his previous paper in No. 8 of the same journal concerning the inner and outer nucleus of the funiculus cuneatus, the topography of the latter and its relations to the cerebellum: Obertheines, in the recent edition of his book, speaks of the outer nucleus of the funiculus cuneatus as an inconstant group of cells situated peripherally. Blumenan believes that the cells of this nucleus belong to the two types that have been differentiated by Golgi. The nerve processes of these cells, although giving off accessory fibres, do not lose their unity after going a long distance. The nerve processes disperse as a rule lateralwards toward the restiform body and the arcuate fibres which come from the lateral columns of the cerebellum. Others of these fibres can be followed to the lateral periphery of the medulla, where further relations cannot be absolutely made out. There are also cells that send these processes inward but frequently, however, after these have passed a shorter or longer distance, they turn and go toward the periphery.

The author mentions a case of deficient development of the cerebellum which he was permitted to examine in which only a small part of the hemispheres on both sides and a rudimentary nucleus on the right side were developed. The 